\title{
A Review on Intergroup Relationship between Hindu and Muslims in Jammu and Kashmir (India)
}

\author{
Showket Ahmad Wani ${ }^{1 *}$, Aijaz Ahmad Buhroo ${ }^{2}$
}

\section{ABSTRACT}

Intergroup emotions theory seeks to understand and improve intergroup relations by focusing on the emotions engendered by belonging to, and by deriving identity from, a social group (processes called self-categorization and identification). Intergroup emotions are shaped by the very different ways in which members of different groups see group-relevant objects and events. These emotions come, with time and repetition, to be part and parcel of group membership itself. Once evoked, specific intergroup emotions direct and regulate specific intergroup behaviors. This approach has implications for theories of emotion as well as of intergroup relations. Because intergroup emotions derive from self-categorization and identification and because they strongly influence intergroup behavior, intergroup emotions theory provides an innovative framework for attempts to reduce prejudice and improve intergroup relations. There is a great difference between the Hindus and Muslims in tradition, in history and in their attitude towards life political, social and economic.

\section{Keywords: Intergroup relations, Hindu, Muslims, Jammu \& Kashmir}

Kashmir is located at the junction of Pakistan, India, Afghanistan and China in the Himalayan Mountains. India's Mughal emperors by the beauty of its surroundings called Kashmir paradise. In the last seven decades Kashmir became a paradise lost. Its people were trapped in the current of a bitter dispute between India and Pakistan. It became a focal point of inter-state conflict in the first and second India-Pakistan wars, in 1947-1948 and 1965, started on the dispute over Kashmir, and the territory also saw heavy fighting in the third war in 1971. The conflict over the territory of Kashmir has dominated Indo-Pakistani relations for over fifty years. From its roots from before the independence of India and Pakistan to the modern insurgency which emerged in 1990, the conflict has developed a complicated set of interlocking factors, from religion to material resources, and ethno-linguistic groups. Many of the accusations of India and Pakistan

\footnotetext{
${ }^{1}$ Research Scholars Department of Psychology, Barkatullah University Bhopal, M.P., India

${ }^{2}$ Research Scholars Department of Psychology, Barkatullah University Bhopal, M.P., India

*Responding Author

(C) 2016, S Wani, A Buhroo; licensee IJIP. This is an Open Access Research distributed under the terms of the Creative Commons Attribution License (http://creativecommons.org/licenses/by/2.0), which permits unrestricted use, distribution, and reproduction in any Medium, provided the original work is properly cited.
} 
regarding Kashmir can still be traced to this period from partition to the UN cease-fire in 1949. Indeed, much of the rationale behind India and Pakistan's continued claims to Kashmir rest on the sequence of events. As each nation interpreted the other's action as an imposition - unlawful, illegitimate and aggressive, the situation worsened, transforming into the intractable positions that India and Pakistan align to this day.

For this reason the intergroup relationship between Hindu \& Muslims must be different from rest of the India. Keeping this in mind I have chosen to analyze these intergroup relations between Hindu and Muslims in the state of Jammu \& Kashmir.

\section{REVIEW OF LITERATURE}

Taylor \& Jaggi (1947) had worked on Ethnocentrism and causal Attribution in a south Indian Context and studied that status differentiation in intergroup relations exercise a significant influence in determining intergroup attitudes and relations.

Allport, (1954) has worked on the nature of prejudice and found that according to the social learning view, children acquire negative attitudes toward various social groups because they hear such views expressed by parents, teachers and others, and because they are directly rewarded for adopting these views. "Prejudice was not taught by the parent, but was caught by the child from the infected environment”. Allport, (1954) Bandura, (1977) \& Mischel,(1966) have worked on social learning view of sex differences in behavior \& Social learning theory and they suggested that prejudice is learned and it develops in much the same manner and through the same basic mechanism as other attitudes. Campbell, D. T. (1956) had worked on Enhancement of contrast as a composite habit and studied that the social identification model considers social categorization as a cognitive process, which produces stereotypical perceptions. An important facet of stereotyping is an enhancement of the contrast between groups as the basic consequence of categorization. Schachter \& Singer (1962) had worked on Cognitive, social, and physiological determinants of emotional state and studied that intergroup emotions feel pretty much the same as individual emotions do. If other members of the in group (but not the self) are insulted, for example, people feel anger on behalf of the group, and this anger involves physiological arousal. Just as being personally insulted makes people feel tense and upset, so too does having ones in group insulted. And just as individual anger can be dissipated by attributing some of the attendant upset and anxiety to another source so too can the arousal caused by an in group insult ,Such findings indicate that physiological arousal is an inherent component of group-basedanger, just as it is of individual anger. Lambert and Klineberg (1967) had worked on Children's view of foreign people and they found that the ethnic attitudes of younger children (6 years) were focused on clearly observable external or physical features (e. g., clothing, language, and social customs). By the age 10, there was a shift to less observable internal or psychological features (e.g., ideologies, personality characteristics). Much differentiation in the responses of older children was also noted, perhaps due to their enhanced and refined language skills. LeVine \& 
Campbell, (1972) had worked on Ethnocentrism: Theories of conflicts, attitudes and group behavior and studied that if confidence in one's ethnic identity leads to "own group glorification", then the outcome is a subtle form of prejudice expressed in strong positive attitude towards the in group and strong negative attitude towards the out-group. Berry, et al., (1977) had worked on Multiculturalism and ethnic attitudes in Canada and suggested that confidence in one's own individual identity can provide a basis for respect for others' identity. Turner \& Brown (1978) had worked on. Social status, cognitive Alternatives \& Intergroup relations. And they studied that high status groups can have an insecure social identity They propose that awareness of cognitive alternatives can be created through two main variables: the status systems perceived instability, defined as the groups perceptions that their respective status position can be changed or even reversed, and its perceived illegitimacy in tajfel's sense. Stephan, et al., (2000) had worked on the Actual and perceived threats operate in most, if not all, intergroup situations. Typically they are portrayed as cognitive processes consisting of thoughts and beliefs about out groups members (e.g., stereotypes), but behavioural associations (i.e., past or intended actions) and emotional reactions also constitute a fundamental source of prejudicial attitudes in intercultural relations. Singh and Khan (1979) had worked on Prejudice in Indian Society and they suggested that development of religious prejudice in children involves two over-lapping stages: (a) Religious identity formation and (b) Religious prejudice formation. Religious identity formation refers to the awareness of belonging to a particular religious group. This stage appears at an early age in childhood. At this stage, children not only display the knowledge of their own and others' religious identity, but also display awareness of some of the ethnic biases (e. g., words and concepts used to describe the members of other groups). Singh (1979) had worked on Development of religious identity and prejudice in Indian children. And he found that socialization of prejudice took place mainly in the family and largely through parental models. Tripathi and Srivastava (1981) had found a relationship between relative deprivation and intergroup attitudes in the context of Hindu/Muslim relations in India. The relatively deprived Muslims displayed more ethnocentric intergroup attitudes. It thus appears that the context of existing intergroup relations within a given societal framework and the consequent status differentiations underline and determine own group and out group attitudes to a considerable extent. Tajfel, (1982), has worked on Social psychology of inter-group relations and found that Social identity seems to evolve from the knowledge of one's membership of a social group together with the value and emotional significance attached to that membership. Spencer (1983) had worked on Children's cultural values and parental rearing strategies and had found some relationship between Black children's ethnocentrism and their mothers' knowledge and beliefs. Devos, et al., (1985) \& Shweder et al.,(1984) had worked on and studied that in contrast in many non-western societies connectedness of humans to each other is a normative imperative entailing interdependence and seeing oneself as part of a larger social relationship. Singh (1985) had worked on Developing secularism and national integration in India and found that religious identity began to take shape in the nursery schools, and got crystallized fairly early in childhood. Tajfel \& Turner, (1986) had studied on the social identity theory of intergroup behavior and 


\section{A Review on Intergroup Relationship between Hindu and Muslims in Jammu and Kashmir (India)}

found that although everyone belongs to groups, some groups are more central, important, and emotionally significant to some individuals than to others. The more central and important the group is to the self, the more an individual identifies with, or derives his or her identity from it. Rajgopal $(1987,81)$ studied on Communal Riots in India New Delhi and found that When the competition happens to be between merchants belonging to two religious groups, communal motives are imputed for the success or the failure of the different groups . Frijda, et al.,(1989) had worked on Relations among emotion, appraisal, and emotional action readiness and found that the most important consequence of intergroup emotions, however, is their influence on behavior. Particular emotions have a privileged association with motivation to act. Rydell et al., (1990) had worked on Arousal, processing, and risk taking: Consequences of Intergroup Anger and studied that Intergroup anger aroused by insult or threat of harm to the in group carries the same consequences. People experiencing intergroup anger both fail to carefully analyze the content of a persuasive message and opt for more risky solutions to dilemmas than do people not so affected. Brewer (1991); Kenworthy et al., (2001) had studied on Perceptual asymmetry in consensus estimates of majority and minority members \& the social self and they indicated that the salience of numerical minority status is aversive, and it motivates individuals to protect the validity of their in-group membership in an inter-group context. Varshney, A (1991) had studied on India, Pakistan and Kashmir: Antinomies of Nationalism and found that the manifestation of the Kashmir dispute along religious lines has bolstered the strength of the Hindu nationalists across the country, who have pinned the issue to the question of the loyalty of the Muslim community as a whole towards India. DeRidder and Tripathi (1992) have studied on Norm violation and inter-group relations and they indicated that in the case of co-existing groups, two general classes of power, called" resource power" and "retaliation power", are distinguished. The Hindu and Muslim are the co-existing groups in our country. As a majority group, Hindus generally perceive themselves as resourceful and want to offer any token to own group members. On the other hand, Muslims perceive themselves as a relatively deprived group and find unable to provide beneficial opportunities to their own group members. In this state of affairs, they try their best to prevent own group against any negative outcome. Deaux, K, et al., (1993) had worked on the Reconstructing social identity. Personality and Social Psychology and found that at Very early in our lives, we begin to learn who we are. We develop a social identity, or a selfdefinition that includes how we conceptualize ourselves, including how we evaluate ourselves.

Bodenhausen, et al., (1994) \& Levine (1996) had worked on Negative affect and social judgment: The differential impact of anger and sadness. And studied that Individual anger also has the consequence of increasing confidence, which in turn affects how an angry person deals with his or her environment. Angry people tend not to process information in the environment particularly carefully. Augoustinos, M. et al., (1995) had worked on Social cognition and studied that One offshoot of social identification is prejudice, which is reflected in a low preference and interpersonal attraction among the members of different groups. Many theorists view prejudice as a natural and inevitable consequences of the functional need to categorize individuals into 


\section{A Review on Intergroup Relationship between Hindu and Muslims in Jammu and Kashmir (India)}

their respective social groups Prejudice is an expression of unfavorable attitudes towards an individual or individuals because of their membership of particular group. Fiske (1998) had worked on Stereotyping, Prejudice, and Discrimination and studied that most explanations of intergroup antipathy focus on the false or biased beliefs (or stereotypes) one group might have about another. Devine et al., (2002) had worked on The regulation of implicit race bias: The role of motivations to respond without prejudice and studied that individuals who wish to regulate their own possible prejudice might do so deliberately by changing their current psychological group affiliation. Esses et al., (2002) \& Mackie et al., (2000) had worked on The role of emotions in determining willingness to engage in intergroup contact and studied that Indeed, anger and disgust toward an out group predict both unwillingness to engage in contact with the group and desire to attack that group. Miller et al., (2004) had worked on Effects of intergroup contact and political predispositions on prejudice: Role of Intergroup Emotions and studied that increased contact with members of another group - at least under the right conditions - decreases prejudice against them. We have demonstrated that intergroup contact has this beneficial effect when it produces certain kinds of out group-directed intergroup emotions. McGarty et al., (2005) had studied on Group-based guilt as a predictor of commitment to apology and found that Intergroup guilt, guilt suffered because of an in-group's historically exploitative actions, increases the desire for the in group to apologize to the out group. Bano, S., \& Mishra, R. C. (2006) had worked on the effect of schooling on the development of social identity and prejudice in Hindu and Muslim children and found that Development of identity and prejudice in India seems to follow a different pattern because of certain peculiar features of the social context in which the groups are nurtured. Studies have generally compared Hindu and Muslim groups, using the majority-minority dimension of group categorization. It is indicated that Muslims constitute the largest single minority group where ethnicity and religion seems to be fused together. Gordijn, E. H., et al.,(2006) had worked on Emotional reactions to harmful intergroup behavior and they found that Self categorization also influences people's emotional reactions to specific events and objects that affect their group. Maitner, et al., (2006) had studied on Evidence for the regulatory function of intergroup emotion: Implementing and impeding intergroup behavioral intentions and studied intergroup guilt is diminished when the in group makes reparations, but is exacerbated when the ingroup aggresses again. Maitner et al., (2007) had worked on Antecedents and consequences of satisfaction and guilt following in group aggression. and studied that if groups feel satisfaction rather than guilt after acting aggressively, support for similar aggression goes up. Smith et al., (2007) had worked on Can emotions be truly group level? Evidence for four conceptual criteria. And they studied that specific intergroup emotions produce specific action tendencies. Because intergroup emotions are group-level, so too the behaviors they motivate often are as well. Diane M. Mackie et al.,(2008) had worked on the Intergroup Emotions and Intergroup Relations and studied that Intergroup emotions are

shaped by the very different ways in which members of different groups see group-relevant objects and events. These emotions come, with time and repetition, to be part and parcel of group membership itself. Once evoked, specific intergroup emotions direct and regulate specific 


\section{A Review on Intergroup Relationship between Hindu and Muslims in Jammu and Kashmir (India)}

intergroup behaviors. This approach has implications for theories of emotion as well as of intergroup relations. Jeanita M. Battye \& Anita S. Mak (2008) have worked on Intercultural Communication Barriers, Contact Dimensions and Attitude towards International Students and found that intercultural communication emotions (ICE) were moderately and uniquely related to unfavorable attitudes towards international students. The quantity and quality of social contact exhibited small positive effects on intergroup evaluations and this relationship was partially mediated by ICE. Seger et al., (2008) had worked on Subtle activation of a social categorization triggers group-level emotions. And studied that self-categorization determines emotional reactions, and identification with the group by and large heightens impact. Such findings do rely on heavy-handed reminders of group membership or social pressure to get people to think like group member. Shifts away from the emotions people experience as unique individuals, and convergence on the emotions shared with other group members, are just as readily triggered by the sound of a school song or national anthem, or by subtle exposure to group symbols. Bano S. (2013) had worked on Socialization of prejudice in Hindu and Muslim children and she found that children of both Hindu and Muslim groups become aware of their own group identity as well as that of others at an early age. It also suggests that the development of prejudice in Hindu and Muslim children tends to be significantly linked with the prejudice of their mothers. Dube O. \& J. Vargas (2013), had worked on Commodity Price Shocks and Civil Conflict and studied that the economic progress of one's enemies may heighten the resentment and spite that one "primordially" feels. But equally, there could be the systematic use of violence for economic gain, for the control - via appropriation or systematic exclusion - of property, occupations, business activity and resources. Mitra A. et al., (2013) worked on Implications of an economic theory of conflict: Hindu-Muslim Violence in India and studied that an increase in per-capita Muslim expenditures generates a large and significant increase in future religious conflict. An increase in Hindu expenditures has negative or no effect. This robust empirical finding, combined with the theory, suggests that Hindu groups have been primarily responsible for Hindu- Muslim violence in post-Independence India.

\section{CONCLUSION}

In this article attempts were made to cover all the related data regarding Intergroup Relationship that were published in various journals, books, Thesis from the past. In this paper we have attempted to show Intergroup Relationship between Hindu and Muslims in Jammu and Kashmir (India) and this relationship will be increased only when contact with members of another group is made and at least under the right conditions, then it decreases prejudice against them. It has also been demonstrated that intergroup contact has this beneficial effect when it produces certain kinds of out group-directed intergroup emotions.

\section{Acknowledgments}

The author appreciates all those who participated in the study and helped to facilitate the research process. 


\section{Conflict of Interests}

The author declared no conflict of interests.

\section{REFERENCES}

Allport, G. W. (1954). The nature of prejudice. Cambridge, Mass: Addison Wesley.

Bandura, A. (1977). Social learning theory. Englewood Cliffs, NJ: Prentice Hall.

Varshney A. (1991) "India, Pakistan and Kashmir: Antinomies of Nationalism,” Asian Survey, Vol. 31, No. 11, pp. 997-1019, 1991.

Augoustinos, M; and Walker, I. (1995). Social cognition: An integrated introduction. London:Sage.

Berry, J. W; Kalin; \& Taylor, D. M. (1977). Multiculturalism and ethnic attitudes in Canada. Ottawa: Ministry of Supply and Services.

Brewer, M. B. (1991). The social self: On being the same and different at the same time. Personality and Social Psychology Bulletin, 17, 475-482.

Bodenhausen, G. V., Sheppard, L. A., \& Kramer, G. P. (1994). Negative affect and social judgment: The differential impact of anger and sadness. European Journal of Social Psychology. Special Issue: Affect in social judgments and cognition, 24, 45-62.

Brown, R. (1995). Prejudice: Its social psychology. Cambridge, MA: Blackwell.

Bano, S., \& Mishra, R. C. (2006). The effect of schooling on the development of social identity and prejudice in Hindu and Muslim children. Indian Journal of Community Psychology, 2, 168-182.

Battye, J. M. \& Mak, A. S. (2008). Intercultural communication barriers, contact dimensions and attitude towards international students. In Voudouris, N. \& Mrowinski, V. (Eds.), Proceedings of the 43rd Australian Psychological Society Annual Conference (pp. 2125), Hobart, September 23-27.

Bano.S (2013). Socialization of prejudice in Hindu and Muslim children. Online International Interdisciplinary Research Journal, \{Bi-Monthly\}, ISSN2249-9598, Volume-III, IssueIII, May-June 2013.

Campbell, D. T. (1956). Enhancement of contrast as a composite habit. Journal of Abnormal and Social Psychology, 53, 350-355.

Devos G., Marsella A. \& Hsu F. L. K. (1985). Dimensions of the self in Japanese culture. Culture and self (pp. 181-184). London : Tavistock.

DeRidder, R; \& Tripathi, R. C. (1992). Norm violation and inter-group relations. Oxford: Clarendon Press.

Deaux, K. (1993). Reconstructing social identity. Personality and Social Psychology Bulletin, 19, 4-12.

Devine, P. G., Plant A. E., Amodio, D. M., Harmon-Jones, E., \& Vance, S. L. (2002). The regulation of implicit race bias: The role of motivations to respond without prejudice. Journal of Personality and Social Psychology, 82, 835-848.

Diane M., Eliot R. Smith and Devin G. Ray Intergroup Emotions and Intergroup Relations Social and Personality Psychology Compass 2/5 (2008): 1866-1880, 10.1111/j.17519004.2008.00130.x Department of Psychology, University of California, Santa Barbara 2 Department of Psychological and Brain Sciences, Indiana University. 
Dube, o. and J. Vargas (2013), "Commodity Price Shocks and Civil Conflict: Evidence from Colombia," forthcoming, Review of Economic Studies.

Ellemers, N; Wike, H; \& VanKnippenberg, A. (1993). Effect of the legitimacy low group or individual status as individual and collective status-enhancement strategies. Journal of Personality and Social Psychology, 64, 766-778.

Esses, V. M., \& Dovidio, J. F. (2002). The role of emotions in determining willingness to engage in intergroup contact. Personality and Social Psychology Bulletin, 28, 1202-1214.

Frijda, N. H., Kuipers, P., \& ter Schure, E. (1989). Relations among emotion, appraisal, and emotional action readiness. Journal of Personality and Social Psychology, 57, 212-228.

Fiske, S. T. (1998). Stereoytping, Prejudice, and Discrimination. In D. T. Gilbert, S. T. Fiske, \& G. Lindzey (Eds.), The Handbook of Social Psychology (4th ed., pp. 357-411). New York, NY: McGraw-Hill.

Gordijn, E. H., Yzerbyt, V., Wigboldus, D., \& Dumont, M. (2006). Emotional reactions to harmful intergroup behavior. European Journal of Social Psychology, 36, 15-30.

Kenworthy, J. B; \& Miller, N. (2001). Perceptual asymmetry in consensus estimates of majority and minority members. Journal of Personality and Social Psychology,80, 597- 612.

Lambert, W. E; \& Klineberg, O. (1967). Children's view of foreign people. New York: Appleton Century Crofts.

Levine, R. A. \& Campbell, D. T. (1972). Ethnocentrism: Theories of conflicts, attitudes and group behavior. New York: Wiley.

Levine, L. J. (1996). The anatomy of disappointment: A naturalistic test of appraisal models of sadness, anger, and hope. Cognition \& Emotion, 10, 337-359.

Mischel, W. (1966). A social learning view of sex differences in behaviour. In E. E. MacCoby (Eds.) The development of sex difference (pp.25-55). Stanford. CA: Stanford University Press.

Mackie, (2000). Intergroup emotions: Explaining offensive action tendencies in an intergroup context. Journal of Personality and Social Psychology, 79, 602-616.

Miller, D. A., Smith, E. R., \& Mackie, D. M. (2004). Effects of intergroup contact and political predispositions on prejudice: Role of Intergroup Emotions. Group Processes and Intergroup Relations, 7, 221-237.

McGarty, C., Pedersen, A., Leach, C. W., Mansell, T., Waller, J., \& Bliuc, A. M. (2005). Groupbased guilt as a predictor of commitment to apology. British Journal of Social Psychology, 44, 659-680.

Maitner, A. T., Mackie, D. M., \& Smith, E. R. (2006). Evidence for the regulatory function of intergroup emotion: Implementing and impeding intergroup behavioral intentions. Journal of Experimental Social Psychology, 42, 720-728.

Maitner, A. T., Mackie, D. M., \& Smith, E. R. (2007). Antecedents and consequences of satisfaction and guilt following ingroup aggression. Group Processes and Intergroup Relations, 10, 225-239.

Mitra. A. \& Ray D. (2013). Implicatios of an economic theory of conflict:Hindu-Muslim Violence in India: Journal of Economic Literature Classification Numbers: C33, D31, D74.

Rajgopal, P. (1987). Communal Riots in India. New Delhi: Uppal Pub. (for Centre Policy Res). Rydell, R. (1990) Arousal, processing, and risk taking: Consequences of Intergroup Anger. Personality and Social Psychology Bulletin. 
Schachter, S., \& Singer, J. (1962). Cognitive, social, and physiological determinants of emotional state. Psychological Review, 69, 378-399.

Singh, S. N; \& Khan, H. R. (1979). Prejudice in Indian Society. Varanasi, Rupa psychological center.

Singh, A. K. (1979). Development of religious identity and prejudice in Indian children. Social Action, 29, 328-240.

Spencer, M. B. (1983). Children's cultural values and parental rearing strategies.Developmental Review, 3, 351-370.

Shweder, R.A., \& Bourne, E.J. (1984). Does the concept of the person vary cross-culturally? self and emotion Cambridge, England.

Shweder R.A. \& R.A.Levine (Eds.), Culture theory : Essay on mind, self and emotion(pp. 158199). Cambridge, England: Cambridge University Press.

Singh, A. K. (1985). Developing secularism and national integration in India.Presidential address to The Section of Psychology and Educational Sciences,the 72nd Session of Indian Congress, Lucknow.

Stephan, W. G., Diaz-Loving, R., \& Duran, A. (2000). Integrated threat theory and intercultural attitudes. Journal of Cross-Cultural Psychology, 31, 240-249.

Smith, E. R., Seger, C. R., \& Mackie, D. M. (2007). Can emotions be truly group level? Evidence for four conceptual criteria. Journal of Personality and Social Psychology, 93, 431-446.

Seger, C., Smith, E. R., \& Mackie, D. M. (2008). Subtle activation of a social categorization triggers group-level emotions. Unpublished manuscript, Indiana University.

Taylor, D,M. and Jaggi, V (1974). Ethnocentrism and causal Attribution in a south Indian Context . Journal of cross-culture Psychology, 5, 162-72.

Turner, J.C. \& Brown, R.(1978). Social status, cognitive Alternatives \& Intergroup relations. London :Academic Press.

Tripathi, R.C. and Srivastava, R. (1981) relative deprivation and intergroup attitudes. European journal of social Psychology, 11, 313-18.

Tajfel, H. (1982). Social psychology of inter-group relations. Annual Review of Psychology, 33, 1-30.

Tajfel, H., \& Turner, J. C. (1986). The social identity theory of intergroup behavior. In S. Worchel \& W. G. Austin (Eds.), Psychology of Intergroup Relations, 2nd ed. Chicago, IL:Nelson-Hall.

How to cite this article: S Wani, A Buhroo (2016), A Review on Intergroup Relationship between Hindu and Muslims in Jammu and Kashmir (India), International Journal of Indian Psychology, Volume 3, Issue 4, No. 74, ISSN:2348-5396 (e), ISSN:2349-3429 (p), DIP:18.01.024/20160304, ISBN:978-1-365-46362-4 